\title{
UNUSUAL CASE OF RETROPHARYNGEAL HEMATOMA WITH USE OF ORAL ANTICOAGULANT THERAPY - CASE REPORT AND REVIEW OF LITERATURE
}

\author{
Authors: Srujan Vallur ${ }^{1}, V_{i k a s}$ Gupta ${ }^{2}$, Abhijit Basu $^{3}$, Kiran Upadhyay $^{4}$, Ritika Bhatia $^{5}$, Madhav N $^{6}$
}

\section{Authors Affiliations:}

(1) Dept of ORL-HNS, 12 Airforce Hospital, Gorakhpur, (2) Associate Prof, (3) Assistant Prof. (4) Assistant Prof, (5) Senior Resident, (6) Resident, Dept of ORL-HNS, Command Hospital, Lucknow.

\begin{abstract}
Retropharyngeal space is a rare site of spontaneous haemorrhage and the formation of a hematoma in this location is a rarer complication of therapy with anticoagulants. Airway compromise can occur in rapidly increasing retropharyngeal hematoma. Emergent airway stabilisation is the key to a successful management of such cases, apart from reversal of causative factor.

We report a case of spontaneous retropharyngeal hematoma in an elderly female on anticoagulant therapy for Rheumatic heart disease, and has developed rapidly progressive swelling in neck, post bout of violent cough. She was successfully managed with emergent airway access and reversal of causative factors.
\end{abstract}

Keywords: Retropharyngeal hematoma, Retropharyngeal space, Anticoagulant therapy

\section{Introduction}

The retropharyngeal space (RS) contains lymph nodes and is bounded anteriorly by the middle layer of deep cervical fascia and posteriorly by the alar fascial component of the deep layer of deep cervical fascia. It extends cranio-caudally from the skull base to the tracheal bifurcation. A midline raphe is formed by the attachment of the superior constrictor muscles to the alar fascia [1].

Retropharyngeal hematoma $(\mathrm{RH})$ is uncommon but potentially life threatening condition usually caused in adults by penetrating trauma through the posterior mucosal wall of the pharynx or cervical oesophagus. This rare entity may also occur as a result of different causes, including cervical spine trauma[2], intrathyroid bleeding[3], rheumatoid arthritis [4], EpsteinBarr virus infection [5], surgery [6], great vessel trauma, violent head movements, internal jugular vein puncture, parathyroid adenoma haemorrhage, and foreign body ingestion[7]. It may also occur spontaneously in patients with bleeding diatheses and in patients who are taking anticoagulation therapy[8]. Retropharyngeal hematoma is a significant cause of airway compromise and the most appropriate treatment from among the available options are, intubation, tracheotomy, and conservative wait and watch approach or surgical intervention by external drainage after securing airway [9][10][11]

We report a case of retropharyngeal hematoma that occurred spontaneously in a patient with a rheumatic heart disease with mitral stenosis who was taking anticoagulation therapy. We also review the literature on retropharyngeal hematoma.

\section{Case report}

60 years old lady, presented to emergency department of a peripheral hospital, with history of swelling over a neck of one day duration along with mild odynophagia. There was no history of fever, prior pain or swelling 
over neck. On going through her old medical documents she was found to be a known case of Rheumatic heart disease with mitral stenosis on systemic anticoagulant therapy (tab Warfarin) apart of medication for systemic illness. She denied any obvious history of sustaining trauma to neck. There was no history ingesting non vegetarian food, which could cause trauma to posterior pharyngeal wall due to bony spicule. She only gave h/o dry cough in bouts. At this juncture $\mathrm{RH}$ due to possibility of spontaneous intrathyroidal bleed as a result of bout of violent cough as an inciting factor was considered.

On examination, there was diffuse swelling over neck, anteriorly as well as laterally with slight predominance towards left (Fig 1). There was no stridor or noisy breathing. Her vital were within normal physiological limits, she was maintaining $\mathrm{SPO}_{2}$ on room air.

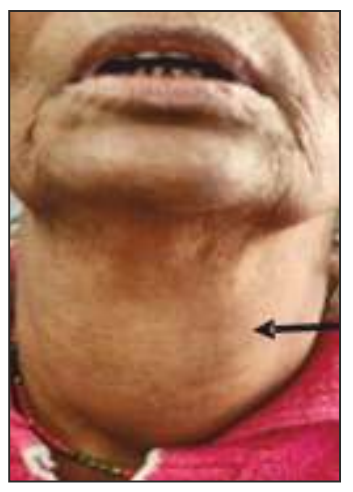

Fig 1: Diffuse swelling over neck, predominantly on left (arrow)

An urgent fibreoptic laryngoscopy (FOL) revealed ecchymosis and swelling in endolarynx involving posterior pharyngeal wall, aryetenoids, however bilateral vocal cords were mobile and glottis chink was adequate (Fig 2). An urgent complete blood counts with INR was done. INR was grossly deranged with a value of 10.1 .

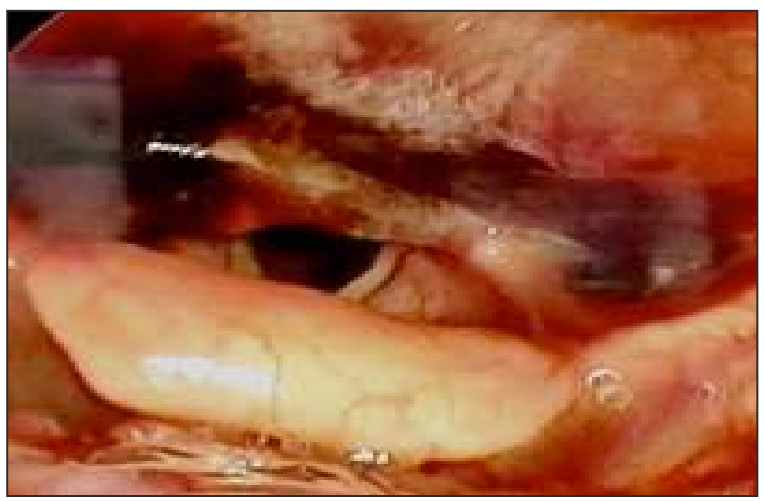

Fig 2: Submucosal ecchymosis and swelling involving posterior pharyngeal wall (arrow)Urgent USG neck followed by urgent CECT revealed collection in $\mathrm{RS}$ along with extension into parapharyngeal space, measuring $5 \times 2 \times 4 \mathrm{~cm}$ extending from skull base superiorly to level of glottis inferiorly (Fig 3). It was $14.4 \mathrm{~mm}$ at C2 vertebra level, $19.8 \mathrm{~mm}$ at C3,C4 level and $16.5 \mathrm{~mm}$ at C7 level. There was no collection inside thyroid capsule

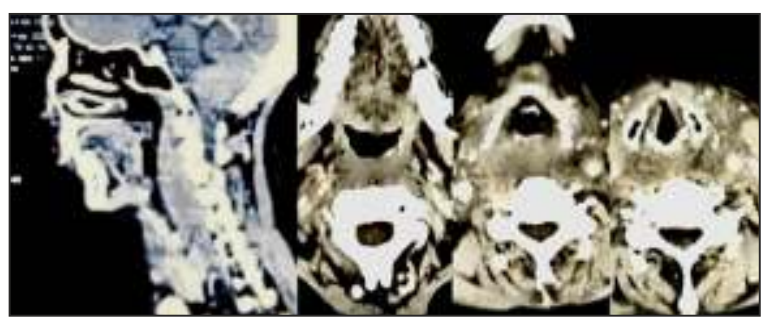

(Fig 3 There were no findings suggestive intracranial bleed, gastro-intestinal bleed, spontaneous mucosal bleed, haematuria or haemarthrosis.

Fig 3: CECT- sagittal and axial view, showing collection in retropharyngeal space at different levels

In view of swelling extending to anterior neck, and adequate glottis chink on FOL, an urgent consultation with Intensivist was done, and it was decided to electively intubate her, to secure the airway. An informed written consent from patient and next of kin was taken. Apart of this local ice packs were applied, along with prophylactic broad spectrum antibiotics. She was also given Vit K $10 \mathrm{mg} / \mathrm{ml}$ IV daily. Fresh frozen plasma transfusion was also performed along with cessation of tab warfarin. She was later transferred to a tertiary care centre.

On arrival to our centre, patient was stable, on ETT with T-piece and room air. The swelling has reduced. Her INR has reduced to 3 . A conservative approach was decided. A repeat MRI was done to assess for present status of $\mathrm{RH}$. Repeat MRI on $4^{\text {th }}$ post intubation day, revealed significant resolution of $\mathrm{RH}$ (Fig 4), with maximum thickness of $\mathrm{RS}$ of $6 \mathrm{~mm}$ at $\mathrm{C} 2,7.1 \mathrm{~mm}$ at C3, C4 level and 6.3mm at C7 level. 


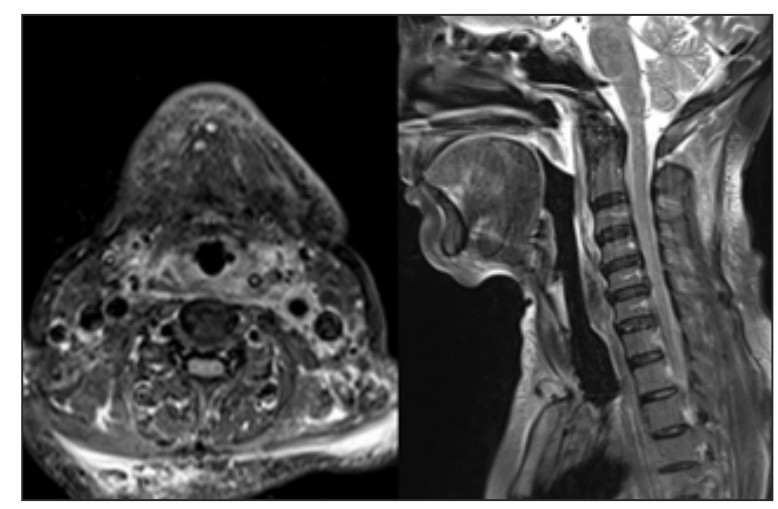

Fig 4: T2w images on MRI showing resolution of retropharyngeal collection.

Repeat FOL also revealed marked regression in swelling over posterior pharyngeal wall. Later her INR returned to normal limits. She was extubated successfully on $5^{\text {th }}$ post intubation day. She maintained $\mathrm{SPO}_{2}$ on room air. Cardiologist opinion was also taken for her systemic disease and re initiation of anticoagulants. On followup at 02 months, patient is asymptomatic.

\section{Discussion}

The retropharyngeal space is the area ofloose connective tissue that lies between the middle (buccopharyngeal) and the alar layers of the deep cervical fascia [12][13]. It extends from the base of the skull to the place where the two layers fuse at a variable level between the $\mathrm{C} 7$ and T4 vertebrae[13]. As a result, bleeding into the retropharyngeal space can extend from the skull base to the mediastinum. In addition, because the pretracheal, parapharyngeal, and retropharyngeal spaces are in communication with each other, a hematoma or an infection in one of these spaces can easily spread to the others.

Anticoagulation is routinely used to prevent thromboembolism in patients with atrial fibrillation and patients who undergo some cardiac surgical procedures, such as mechanical valve replacement. The agent most commonly used for this purpose is warfarin. Warfarin inhibits the vitamin-K-dependent enzymes needed for activation of coagulation factors II, VII, IX, and X. The half-life of warfarin is 35 hours, and its anticoagulant effect lasts 3 to 5 days [12]. Bleeding, the major complication of anticoagulation therapy can occur spontaneously or after a trivial trauma[8]. An elevated INR $(>4.5)$ is associated with a higher risk of bleeding [8]. Over anticoagulation can occur as a result of intercurrent medical conditions or interactions with some medications.

Retropharyngeal hematomas exhibit similar manifestations, including superior mediastinal obstruction (tracheal and oesophageal compression), ventral tracheal displacement on lateral cervical x-rays, and the subsequent appearance of subcutaneous bruising over the anterior neck and upper chest wall [5] [7]. However, because the clinical picture is often obscure at the outset, a high level ofsuspicion is essential for a diagnosis of retropharyngeal hematoma.

Stabilization of the patient's airway is paramount given the risk of rapid expansion of hematoma into the loose connective tissue lying between the pharynx and alar layer of the prevertebral fascia which can dramatically compromise the airway. A careful immediate intubation with either direct laryngoscopy or fiberoptic intubation can be performed with all efforts made to minimize airway trauma given the theoretical concern of hematoma rupture.Emergent tracheostomy can be considered as an alternative but generally not performed as long as patient can be intubated. Tracheostomy is also fraught with fear due to distorted anatomy as hematoma extends anterolaterally.Occasionally, if the swelling is not does not pose immediate threat to airway, patient may be carefully observed without airway access [3][14][15].

Irrespective of which decision is made, it should be made quickly because a delay in the initiation 
of airway management can increase the difficulty of intubation or tracheotomy and thereby magnify the chances of a poor outcome, including death.

Once airway is stabilized, attention can be turned to hematoma control. In most cases, observation and supportive treatment are adequate and suitable. Surgical exploration and evacuation of the hematoma are usually recommended for cases of expansile hematoma [7][8] [14][17]

There is no consensus on the management of a compromised airway caused by a retropharyngeal hematoma. On the basis of our experience, and literature review, we suggest that a small non-expanding hematoma, not compromising the airway can be managed conservatively. Securing the airway with intubation or tracheotomy should be reserved for patients who are in serious respiratory distress; the choice between intubation and tracheotomy should be made on case to case basis.

Cross sectional imaging (computed tomography or magnetic resonant imaging with or without contrast) plays a vital role in initial as well as follow up of such patients. A deliberate decision to keep the patient on conservative management or surgical intervention can be taken depending upon imaging findings. In the adult, the average width of the retropharyngeal soft tissue at the level of $\mathrm{C} 2$ is $3.5 . \mathrm{mm}$ and at C6 is $14 . \mathrm{mm}$. Any increase in the width of the soft tissue shadow is suggestive of pathology in the retropharyngeal space. [3]

Penning reported that normal prevertebral soft tissue widths were $4.6 \mathrm{~mm}, 3.2 \mathrm{~mm}, 3.4 \mathrm{~mm}$, and $5.1 \mathrm{~mm}$ at $\mathrm{C} 1, \mathrm{C} 2, \mathrm{C} 3$, and $\mathrm{C} 4$ level in the neutral position, and $14.9 \mathrm{~mm}, 15.1 \mathrm{~mm}, 13.9 \mathrm{~mm}$ at C5, C6, and C7 level in neutral position [19]. Rojas et al reported that the upper limits of normal range for thickness of prevertebral soft tissue were 8.5 $\mathrm{mm}, 6 \mathrm{~mm}, 7 \mathrm{~mm}, 18 \mathrm{~mm}$, and $18 \mathrm{~mm}$ at C1, C2, C3, C6, and C7, respectively. The upper limit of normal range was not determined for $\mathrm{C} 4$ and $\mathrm{C} 5$ levels due to variable position of the esophagus and larynx. Furthermore, they reported that mean prevertebral soft tissue thickness were 7 $\mathrm{mm}$ at $\mathrm{C} 4$ and $12.4 \mathrm{~mm}$ at $\mathrm{C} 5$ on multi-detector CT images [19].

Muñoz et al [20] reported that in spontaneously developed hematoma, nearly complete absorption was observed after 1 week. In our case, symptoms gradually alleviated and patient's general condition improved. She was later discharged after 1 week and advised to follow up regularly. Patient has thereafter been asymptomatic on follow up at 2 months.

\section{Conclusion}

Retropharyngeal hematomas due to anticoagulant therapy, are rare yet potentially life threatening emergency due the proximity to the upper airway. A high index of suspicion for $\mathrm{RH}$ should be kept in mind in patients presenting with rapidly progressive neck swelling on anticoagulant therapy even without obvious history of inciting factor. An expeditious management of airway is of paramount importance. Conservative or surgical evacuation of hematoma will depend on close monitoring of hematoma.

\section{Conflict of Interests}

We have no conflict of interests to declare.

\section{Consent}

A written informed consent has been taken from the patient for publication of pictures in medical journal.

\section{References}

1. Moore KL, Dalley AF, Agur AM. Clinically oriented anatomy. Lippincott Williams \&Wilkins; 2013 Feb 13. 
2. El Kettani C, Badaoui R, Lesoin FX, Le Gars D, Ossart M. Traumatic retropharyngeal hematoma necessitating emergency intubation. Anesthesiology: The Journal of the American Society of Anesthesiologists. 2002 Dec 1;97(6):1645-6.

3. Paleri V, Maroju RS, Ali MS, Ruckley RW. Spontaneous retro-and parapharyngeal haematoma caused by intrathyroid bleed. The Journal of Laryngology \& Otology.2002 Oct;116(10):854-8.

4. Thatcher J, George D. Retropharyngeal hematoma as a new cause of acute upper airway obstruction in rheumatoid arthritis. The Journal of rheumatology. 1987 Dec;14(6):1172-3.

5. Jones TM, Owen GO, Morar P. Spontaneous retropharyngeal haematoma attributable to Epstein-Barr virus infection. The Journal of Laryngology \& Otology. 1996 Nov;110(11):1075-7.

6. Daniello NJ, Goldstein SI. Retropharyngeal hematoma secondary to minor blunt head and neck trauma. Ear, nose \& throat journal. 1994 Jan;73(1):41-3.

7. Bloom DC, Haegen T, Keefe MA. Anticoagulation and spontaneous retropharyngeal hematoma. The Journal of emergency medicine. 2003 May 1;24(4):389-94.

8. Bapat VN, Brown K, Nakas A, Shabbo F. Retropharyngeal hematoma-a rare complication of anticoagulant therapy. European journal of cardio-thoracic surgery. 2002 Jan 1;21(1):117-8.

9. Baldassari CM, Howell R, Amorn M, Budacki R, Choi S, Pena M.
Complications in pediatric deep neck space abscesses. Otolaryngology--Head and Neck Surgery. 2011 Apr;144(4):5925.

10. Elsherif AM, Park AH, Alder SC, Smith ME, Muntz HR, Grimmer F. Indicators of a more complicated clinical course for pediatric patients with retropharyngeal abscess. International journal of pediatric otorhinolaryngology. 2010 Feb 1;74(2):198-201.

11. Park JH, Jeong EK, Kang DH, Jeon SR. Surgical treatment of a life-threatening large retropharyngeal hematoma after minor trauma: two case reports and a literature review. Journal of Korean Neurosurgical Society. 2015 Sep;58(3):304.

12. Sinert R, Scalea T. Retropharyngeal and bowel hematomas in an anticoagulated patient. Academic Emergency Medicine. 1994 Jan;1(1):67-72.

13. Al-Fallouji HK, Snow DG, Kuo MJ, Johnson PJ. Spontaneous retropharyngeal haematoma: two cases and a review of the literature. The Journal of Laryngology \& Otology. 1993 Jul;107(7):649-50.

14. Tsai KJ, Huang YC. Traumatic retropharyngeal hematoma: case report. Journal of Trauma and Acute Care Surgery. 1999 Apr 1;46(4):715-6.

15. Hefer T, Netzer A, Joachims HZ, Golz A. Upper airway obstruction--a rare complication after anti-coagulant therapy. Harefuah. 1993 Mar;124(6):3368.

16. Rosenbaum L, Thurman P, Krantz SB. Upper airway obstruction as a complication of oral anticoagulation therapy: report of three cases. Archives 
of Internal Medicine. 1979 Oct 1;139(10):1151-3.

17. Cohen AF, Warman SP. Upper airway obstruction secondary to warfarininduced sublingual hematoma. Archives of Otolaryngology-Head \& Neck Surgery. 1989 Jun 1;115(6):718-20.

18. Penning L. Prevertebral hematoma in cervical spine injury: incidence and etiologic significance. American Journal of Roentgenology. $1981 \mathrm{Mar}$ 1;136(3):553-61.

19. Rojas CA, Vermess D, Bertozzi JC, Whitlow J, Guidi C, Martinez CR. Normal thickness and appearance of the prevertebral soft tissues on multidetector CT. American Journal of Neuroradiology. 2009 Jan 1;30(1):13641.

20. Muñoz A, Fischbein NJ, de Vergas J, Crespo J, Alvarez-Vincent J. Spontaneous retropharyngeal hematoma: diagnosis by MR imaging. American journal of neuroradiology. 2001 Jun 1;22(6):1209-11.

\section{Source of support: NIL}

\section{Authors' contribution}

SVM and $A B$ prepared the manuscript. KU and RB did review of literature. NM involved in day to day care of patient. VG did supervision and editing of the final draft and is the consultant in charge of the patient.

\section{*Corresponding Author:}

Name: Vikas Gupta

Associate Professor, Dept of ORL-HNS,

Command Hospital, Lucknow

Telephone: 77108899590, E-mail:

vg.enthns@gmail.com ORCID: Vikas Gupta:

https://orcid.org/0000-0002-1739-3993 